\title{
Índice general
}

\section{Vol. 1}

\section{Prólogo}

\section{Discurso inaugural}

\section{Sesiones plenarias}

\section{Edad Media}

Ed. Tobias Leuker

\section{Siglo de Oro}

Ed. Wolfgang Matzat, Javier Gómez Montero y Bernhard Teuber

\section{Teatro}

Ed. Cerstin Bauer-Funke, Wilfried Floeck y Manfred Tietz

\section{Siglos XVIII y XIX}

Ed. Andreas Gelz, Susanne Schlünder y Jan-Henrik Witthaus

\section{Vol. 2}

\section{Literatura contemporánea}

Ed. Mechthild Albert, Jochen Mecke y Carmen Rivero

\section{Literatura hispanoamericana}

Ed. Frank Leinen, Gesine Müller y Sebastian Thies

\section{Cine y medios}

Ed. Hanno Ehrlicher, Sabine Schlickers y Christian von Tschilschke

\section{Historia y cultura}

Ed. Birgit Aschmann, Walther L. Bernecker, Robert Folger y Ulrich Winter

\section{Lengua}

Ed. Sybille Große, Daniel Jacob y Silke Jansen 
